\title{
Health At Risk: Exploring Geographical Differences In Health Risk Factors Among Canada's Aboriginal Population
}

Kathryn Kimery, Saint Mary’s University, USA

Samad Amirkhalkhali, Saint Mary's University, USA

Yasmine Amirkhalkhali, Morneau Shepell, USA

\begin{abstract}
Smoking, obesity, and binge drinking are identified as important behavior-related risk factors for long-term health outcomes. Aboriginal People in Canada have significantly higher self-reported rates of all three of these negative health factors compared to the general population of Canada. Initial results from this study demonstrate that there are significant differences in Aboriginal smoking, binge drinking, and obesity rates depending on province or region of residence. Continued analyses clarify the nature of these geographic effects and provide some important implications for industry and government policy-makers.
\end{abstract}

Keywords: Aboriginal People; Health Economics; Geographical Differences; Aboriginal Peoples Survey; Marginalized Populations

\section{INTRODUCTION}

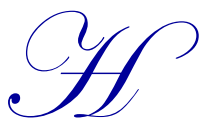

ealth is important to individuals and families, but also to larger communities, businesses, and societies. From an economic perspective, health is valued both as an investment and consumption good and it is an input into production and human capital. Poor health, at an individual level, increases costs for medical care, negatively influences the ability to secure education and training, and reduces earning power. Businesses with an unhealthy workforce must bear the burden of higher absenteeism, turnover, and insurance premiums. Producers of goods and services, with the possible exception of those in the health care industry, also face greater challenges when promoting products and services to consumers who are economically stressed due to widespread health issues. Governments are negatively affected through increased costs for health services, declining productivity and tax flows, and increased uncertainty regarding future economic competitiveness.

Regional conditions can influence health outcomes via multiple mechanisms, including access to health services, environmental phenomena, availability of employment and financial resources, or geographically restricted social stressors. Canada has an economically, politically and geographically diverse landscape. In a previous study by Amirkhalkhali, Kimery, \& Amirkhalkhali (2013), a significant overall effect of region of residence on Aboriginal smoking, binge drinking, and obesity was reported. The current study is focused on identifying the exact loci of differences in rates of smoking, binge drinking, and obesity among Canadian Aboriginals.

Highlights of the full literature review presented in Amirkhalkhali et al. (2013) is next, along with an overview of the Aboriginal Peoples Survey (APS) and description of the dataset used in this study. As reported in the earlier paper, chi-squared analyses of the actual vs. expected rates of daily smoking, binge drinking, and obesity indicate a significant effect of region on each of these health risk factors. Here, the authors present the results of expanded analyses along with conclusions and implications of the research. 


\section{LITERATURE REVIEW}

Aboriginals are constitutionally defined as Metis, First Nations and Inuit who together comprise 4\% of the Canadian population (Richmond \& Ross, 2008). Previous studies have addressed the different determinants for health for Aboriginals in Canada (Curtis, 2007; Denton \& Prus, 2004; Newbold, 1997; Reading \& Wien, 2009; Wilson \& Young, 2008). Rosenberg and Wilson (2002) explore the relationship between health status and specific socio-economic indicators such as education, income and employment. Many of the relationships they demonstrate are as expected; individuals with post-secondary education and current employment were less likely to report being unhealthy. Another important, but not surprising, finding is that those Aboriginals living in cities enjoyed higher socioeconomic status, as well as health outcomes, than those living in rural areas. Rosenberg and Wilson (2002) argue that living in cities offered numerous benefits, such as easier access to hospitals, physicians and medicine, but also other positive contributors toward good health, including public parks, recreational centres, and greater employment opportunity.

Material circumstance is frequently a central factor in research concerning Aboriginal health. Socioeconomic status is almost always an important determinant of general health status for all populations. In general, Aboriginal populations in Canada tend to have lower incomes and be less educated than the non-Aboriginal population (Frohlich, 2006). Furthermore, the Aboriginal unemployment rate, at the time of the study, was $19.4 \%$ compared to the Canadian average of $8.1 \%$. Frohlich's analysis, however, concludes that even at the same levels of income, Aboriginal peoples living off-reserve suffer nearly double the number of chronic health conditions compared to non-Aboriginals.

Researchers have suggested that above and beyond other socio-economic factors, geographical region of residence plays a role in determining health status of Aboriginals. McDonald and Trenholm (2009) observe that the likelihood of being obese is markedly higher for Arctic residents compared to other Aboriginal populations in Canada - about two-and-a-half times more likely. McDonald and Trenholm (2009) assert that since many individuals have relatively low levels of education and live in remote areas, unhealthy decisions - smoking or not regularly seeing a physician - may be further compounded (Richmond \& Ross, 2008). McDonald and Trenholm (2009) suggest policy responses to problems, such as smoking, cannot just be culturally appropriate but must also consider the isolation in places such as the Arctic and other remote reserves.

\section{DATA}

The Aboriginal Peoples Survey (APS), a comprehensive Canadian government survey for those of Aboriginal origin, is the key data source for this study (for more information on this survey, see Curtis, 2007). Data were retrieved from over 30,000 individuals. After necessary exclusions, a usable sample of over 20,000 individuals remains.

The three health determinants examined in this study are smoking, binge drinking, and obesity. Smoking is measured via a question in the APS that asks if the respondent has ever been a daily smoker. The second health factor - "binge drinking" - describes an individual who reports having five or more drinks in one sitting at least once a month. The last factor - "obesity" - describes individuals who report being at least 30 pounds overweight. All three behaviours occur in Aboriginal populations at much higher rates than in the non-Aboriginal populations (Newbold, 1998). The health determinants were chosen because they capture important inputs into overall health status, are easily modeled, and are all addressed in the APS. Furthermore, since the Aboriginal population in Canada is relatively young compared to the non-Aboriginal population and negative health outcomes frequently appear later in life, looking at present health determinants, like drinking, smoking, and obesity, can give us insight into what to expect as the population ages.

This study examines differences in health determinants across six different regions in Canada. The Atlantic region includes the Maritime Provinces (Nova Scotia, Prince Edward Island, and New Brunswick) as well as Newfoundland and Labrador. The prairie provinces (Alberta, Manitoba, and Saskatchewan) and the three territories (Iqaluit, the Northwest Territories, and the Yukon) are also aggregated into separate regions. Quebec, Ontario and British Columbia, because of their larger absolute numbers of Aboriginal residents, are the only provinces evaluated as individual regions. Observations from each region are shown in Table 1. 
Table 1. Observations By Region

\begin{tabular}{|c|c|}
\hline $\begin{array}{r}\text { Regions } \\
\end{array}$ & Observations \\
\hline Atlantic & 3,105 \\
\hline Quebec & 3,196 \\
\hline Ontario & 3,211 \\
\hline Prairies & 6,134 \\
\hline $\mathrm{BC}$ & 2,325 \\
\hline Territories & 2,749 \\
\hline Total & 20,720 \\
\hline
\end{tabular}

\section{ANALYSES AND RESULTS}

Table 2 presents a summary of the rates of daily smoking, binge drinking, and obesity among Canada's Aboriginal people. Regional values were compared pair-wise and evaluated by calculating a chi-squared statistic for each pair.

Table 2. Regional Rates Of Aboriginal Daily Smoking, Binge Drinking, And Obesity

\begin{tabular}{lccc}
\hline \multicolumn{1}{c}{ Region } & Daily Smoking & Binge Drinking & Obesity \\
\hline Atlantic & $32.9 \%$ & $22.0 \%$ & $27.09 \%$ \\
Quebec & $32.79 \%$ & $16.49 \%$ & $18.99 \%$ \\
Ontario & $30.89 \%$ & $21.12 \%$ & $27.5 \%$ \\
Prairies & $29.9 \%$ & $24.5 \%$ & $28.81 \%$ \\
British Columbia & $25.72 \%$ & $22.41 \%$ & $23.61 \%$ \\
Territories & $35.79 \%$ & $52.38 \%$ & $26.81 \%$ \\
National & $31.26 \%$ & $25.83 \%$ & $25.98 \%$ \\
\hline
\end{tabular}

Tables 3-5 present the chi-squared statistic, with the calculated p-value below it, for each comparison. Due to the large number of observations, a relatively strict level of significance was selected $-\alpha=.05$. P-values of less than .05 , then, identify a significant difference between the pairs and are shown in bold in the tables.

Table 3. Paired Comparisons Of Aboriginal Daily Smoking

\begin{tabular}{|c|c|c|c|c|c|c|}
\hline & Atlantic & Quebec & Ontario & Prairies & BC & Territories \\
\hline \multirow{2}{*}{ Atlantic } & & .0109 & 2.968 & 8.7787 & 32.8709 & 5.3698 \\
\hline & & $(.9167)$ & $(.0842)$ & $(.0030)$ & $(<.0001)$ & $(0.0204)$ \\
\hline \multirow{2}{*}{ Quebec } & .0109 & & 2.656 & 8.2324 & 32.1553 & 5.9272 \\
\hline & $(.9167)$ & & $(.1031)$ & $(.0041)$ & $<.0001$ & 0.0149 \\
\hline \multirow{2}{*}{ Ontario } & 2.968 & 2.656 & & .9888 & 17.63 & 16.0520 \\
\hline & $(.0842)$ & $(.1031)$ & & $(.3200)$ & $(<.0001)$ & $(<.0001)$ \\
\hline \multirow{2}{*}{ Prairies } & .9888 & 8.2324 & .9888 & & 14.3701 & 30.4654 \\
\hline & $(.3200)$ & $(.0041)$ & $(.3200)$ & & $(.0001)$ & $(.0001)$ \\
\hline \multirow{2}{*}{$\mathrm{BC}$} & 32.8709 & 32.1553 & 17.63 & 14.3701 & & 59.5807 \\
\hline & $(<.0001)$ & $<.0001$ & $(<.0001)$ & $(.0001)$ & & $(<.0001)$ \\
\hline \multirow{2}{*}{ Territories } & 5.3698 & 5.9272 & 16.0520 & 30.4654 & 59.5807 & \\
\hline & $(0.0204)$ & 0.0149 & $(<.0001)$ & $(.0001)$ & $(<.0001)$ & \\
\hline
\end{tabular}

Note: Chi-squared statistics followed by (p-value); significant results bolded Values displayed to 4 significant digits to right of decimal point 
Table 4. Paired Comparisons Of Aboriginal Binge Drinking

\begin{tabular}{ccccccc}
\hline & Atlantic & Quebec & Ontario & Prairies & BC & Territories \\
\hline \multirow{2}{*}{ Atlantic } & & 30.7882 & .7261 & 64.9439 & .306 & 582.4494 \\
& & $(<.0001)$ & $(.3941)$ & $(<.0001)$ & $(.7177)$ & $(<.0001)$ \\
\hline \multirow{2}{*}{ Quebec } & 30.7882 & & 22.4425 & 79.2588 & 30.6633 & 859.9864 \\
& $(<.0001)$ & & $(<.0001)$ & $(<.0001)$ & $(<.0001)$ & $(<.0001)$ \\
\hline \multirow{2}{*}{ Ontario } & .7261 & 22.4425 & & .13 .5207 & 1.3301 & 632.0795 \\
& $(.3941)$ & $(<.0001)$ & & $(.0002)$ & $(.2487)$ & $(<.0001)$ \\
\hline \multirow{2}{*}{ Prairies } & 64.9439 & 79.2588 & .13 .5207 & & 4.062 & 666.0154 \\
& $(<.0001)$ & $(<.0001)$ & $(.0002)$ & & $(.0438)$ & $(<.0001)$ \\
\hline \multirow{2}{*}{ BC } & .1306 & 30.6633 & 1.3301 & 4.062 & $(.0438)$ & 477.291 \\
& $(.7177)$ & $(<.0001)$ & $(.2487)$ & & $(<.001)$ \\
\hline \multirow{2}{*}{ Territories } & 582.4494 & 859.9864 & 632.0795 & 666.0154 & 477.291 & $(<.001)$ \\
\end{tabular}

Note: Chi-squared statistics followed by (p-value); significant results bolded Values displayed to 4 significant digits to right of decimal point.

Table 5. Paired Comparisons Of Aboriginal Obesity

\begin{tabular}{lcccccc}
\hline & Atlantic & Quebec & Ontario & Prairies & BC & Territories \\
\hline \multirow{2}{*}{ Atlantic } & & 58.2777 & .1362 & 3.014 & 8.417 & .0562 \\
& & $(<.0001)$ & $(.712)$ & $(.0825)$ & $(.0037)$ & $(.8125)$ \\
\hline \multirow{2}{*}{ Quebec } & 58.2777 & & 64.94425 & 106.6837 & 17.3566 & 51.6167 \\
& $(<.0001)$ & & $(<.0001)$ & $(<.0001)$ & $(<.0001)$ & $(<.0001)$ \\
\hline \multirow{2}{*}{ Ontario } & .1362 & 64.94425 & & .1 .7733 & 10.6215 & .3557 \\
& $(.712)$ & $(<.0001)$ & & $(.1829)$ & $(.0011)$ & $(.5509)$ \\
\hline \multirow{2}{*}{ Prairies } & 3.014 & 106.6837 & .1 .7733 & & 22.8732 & 3.7394 \\
& $(.0825)$ & $(<.0001)$ & $(.1829)$ & & $(<.0001)$ & $(.0531)$ \\
\hline \multirow{2}{*}{ BC } & 8.417 & 17.3566 & 10.6215 & 22.8732 & & 6.8036 \\
& $(.0037)$ & $(<.0001)$ & $(.0011)$ & $(<.0001)$ & & $(.009)$ \\
\hline \multirow{2}{*}{ Territories } & .0562 & 51.6167 & .3557 & 3.7394 & 6.8036 & \\
& $(.8125)$ & $(<.0001)$ & $(.5509)$ & $(.0531)$ & $(.009)$ & \\
\hline
\end{tabular}

Note: Chi-squared statistics followed by (p-value); significant results bolded Values displayed to 4 significant digits to right of decimal point

This analysis highlights that British Columbia and the Territories have a rate of daily smoking that is significantly different from all other regions, while the Prairies region has a rate that is significantly different from all regions, with the exception of Ontario. The Territories, the Prairies, and Quebec have rates of binge drinking that differ significantly from all other regions. Finally, in terms of obesity, Quebec and British Columbia have rates that are significantly different from all other regions.

Referring to the observed regional rates of daily smoking, binge drinking, and obesity presented in Table 2 , these differences can be interpreted in a more meaningful way. Comparing the six different regions, the proportion of individuals who identify themselves as having been daily smokers at one time in their lives is, in fact, significantly higher in the Territories. The Atlantic region and Quebec have significantly higher rates of daily smoking than do the Ontario and the Prairies regions. British Columbia has a significantly lower rate than all other regions. Regarding binge drinking - defined as the consumption of five or more alcoholic beverages in one sitting at least once a month - the Territories have the highest rate, by a significant margin, with the Prairies region having a rate significantly lower than the Territories but significantly higher than the Atlantic region, Quebec, Ontario, and British Columbia. At the other end of the spectrum, Quebec has a significantly lower rate of binge drinking than any other region. Lastly, in terms of obesity, Quebec has a significantly lower rate of reported obesity than all other regions, while British Columbia has an obesity rate than is significantly higher than Quebec's, but significantly lower than all other provinces.

In an attempt to consolidate all of these findings into a summarized result, the regions were ordered and ranked based on significant regional differences in the three behavior-related health risk factors - daily smoking, binge drinking, and obesity. The value of 1 was assigned to the region with the lowest factor rate, 2 assigned to the second lowest, and so on, resulting in a possible index range between 3 and 18, inclusive. Regions that did not 
display significant differences in terms of a particular factor were assigned an averaged value. This process resulted in the ranked list presented in Table 6, with the lowest index value indicating the region with the lowest rate of health risk factors and the highest value indicating the region with the highest rate of health risk factors.

Table 6. Regions Ranked In Order Of Behaviour-Related Health Risk Factors

\begin{tabular}{|c|c|}
\hline Region & Index Value \\
\hline British Columbia & 6 \\
\hline Quebec & 6.5 \\
\hline Ontario & 10 \\
\hline Atlantic & 12 \\
\hline Prairies & 12 \\
\hline Territories & 16.5 \\
\hline
\end{tabular}

\section{CONCLUSIONS AND LIMITATIONS}

Aboriginal health in Canada is an important human, business, and government policy issue. Careful analysis of data, such as that collected by the APS, is necessary to help individuals, businesses, and policy-making agencies better understand problems and opportunities facing Aboriginal populations. Data aggregated at a national level, however, may provide an unfocused or slanted picture of the conditions and resulting health outcomes among Aboriginals. The expanded analysis of APS data presented in this study confirms and expands the findings reported in an earlier paper (Amirkhalkhali et al., 2013). Specifically, these results show that : 1) the rate of daily smoking is significantly higher in the Territories than in any other area, while it is significantly lower in British Columbia; 2) binge drinking is significantly more common among Aboriginals in the Territories and significantly less common in Quebec and British Columbia than in other areas; and 3) Aboriginal obesity rates do not vary significantly across the Atlantic, Ontario, Prairies, or Territories, but obesity rates are significantly lower in British Columbia and significantly lower still in Quebec. A ranking of the regions in terms of these three behavior-related health risk factors shows that British Columbia and Quebec are doing much better than other regions, while the Territories are doing much worse. These results are consistent with McDonald and Trenholm's (2009) findings that the Canadian North, including the Yukon, the Northwest Territories, and Nunavut, is a vulnerable region for key health determinants, especially for smoking and binge drinking. This could be due to lack of resources or societal pressures that may exist in more isolated regions (Richmond and Ross, 2009).

In regard to smoking, British Columbia should be looked to as a model for other Canadian regions. Policymakers, especially, should note that British Columbia has the lowest smoking rate of all regions, considerably less than the rate expected based on national data. For obesity and binge drinking, policymakers, human resource experts, and non-governmental agencies could look to Quebec for insight. While rates of smoking may be higher than expected, obesity and binge drinking are noticeably lower than expected based on national rates.

As identified in the previous paper (Amirkhalkhali et al., 2013), certain limitations must be incorporated in any interpretation of these results: 1) The APS is self-reported and, as such, is subject to measurement error; 2) There is a high non-response rate for questions concerning weight and drinking and both are likely to be underreported; and 3) no demographic or socio-economic variables are included in these data. In addition, it should be noted that the APS does not include data from First Nations people living on reserves. Given that most prior studies report lower health status of First Nations members living on-reserve compared to off-reserve, it is likely that this data are biased based on residential patterns in different regions. Lastly, the analyzed data in this study are taken from the 2006 APS - the most current dataset at the time this study began. Recently, the 2012 data have become available and will be analyzed in the near future.

Understanding the regional disparity in health allows both policy makers and health practitioners to design and implement more focused policy initiatives to improve Aboriginal health across Canada. Individual employers and industries benefit from understanding the nature of health conditions in the local and regional areas in which they operate and draw potential employees. The Aboriginal health risk factors considered in this study - daily smoking, binge drinking, and obesity - vary significantly between regions in Canada. In future analyses, the authors will address more specifically whether these differences are determined more by geographic or by interrelated demographic and socio-economic differences in the various regions. 


\section{AUTHOR INFORMATION}

Dr. Kathryn M. Kimery is Associate Professor of Computing and Information Systems at Saint Mary's University in Halifax, Nova Scotia, Canada. Her research focuses on electronic commerce and social aspects of computing. She has published in journals, including Journal of Business Research, Journal of Information Technology Theory and Application, Journal of Electronic Commerce in Organizations, International Journal of Management \& Information Systems; in reading collections; as well as in numerous refereed proceedings.

Dr. Samad AmirKhalkhali is an associate professor of Management Science at Saint Mary's University. He has presented his research papers at many national and international conferences. His publications include numerous conference proceedings, several book chapters, as well as articles in journals such as Canadian Journal of Economics, Economic Modeling, Empirical Economics, International Journal of Management \& Information Systems, Southern Economic Journal, The Statistician (published by the Royal Statistical Society), Journal of Statistical Computation and Simulation, and International Business and Economics Research Journal.

Yasmine Amirkhalkhali earned a M.A. in Economics from Queens University. She is currently an instructor in Management Science at Saint Mary's University and her research interests focus on health economics and international development. She has previously published in Global Business Trends: Contemporary Readings and in refereed conference proceedings.

\section{REFERENCES}

Amirkhalkhali, Y., Kimery, K., \& Amirkhalkhali, S. (2013). Geographical Influences On Determinants of Aboriginal Health In Canada: An Economic Study. Global Business Trends: Contemporary Readings. 2013 Edition, 23-29.

Curtis, L. (2007). Health Status of On- and Off-reserve Aboriginal Peoples: Analysis of the Aboriginal Peoples Survey. Social and Economic Dimensions of an Aging Population Research Papers. Research Paper, 191, McMaster University.

Denton, M., \& Prus, S. (2004). Gender Differences In Health: A Canadian Study of the Psychosocial, Structural and Behavioural Determinants of Health. Social Science and Medicine, 58(12):2585-2600.

Frohlich, K., \& Ross, N. (2006). Health Disparities in Canada Today: Some Evidence and a Theoretical Framework. Health Policy, 79:132-143.

McDonald, J., \& Trenholm, R. (2009). Cancer-related Health Behaviors and Health Service Use among Inuit and Other Residents of Canada's North. Social and Economic Dimensions of an Aging Population Research Papers. Research Paper, 248, McMaster University.

Newbold, B. (1997). Aboriginal Physician Use in Canada: Location, Orientation and Identity. Health Economics, 6(2):715-729.

Reading, C., \& Wien, F. (2009). Health Inequities and Social Determinants of Aboriginal Peoples' Health. National Collaborating Centre for Aboriginal Health fact sheet series.

Richmond, C., \& Ross, N. (2009). The Determinants of First Nation and Inuit Health: A Critical Population Health Approach. Health \& Place, 15(2), 403-411.

Rosenberg M., \& Wilson, K. (2002). Exploring the Determinants of Health for First Nations Peoples in Canada. Social Science and Medicine, 55:2017-2031.

Wilson, K., \& Young, T. (2008). An Overview of Aboriginal Health Research in the Social Sciences: Current Trends and Future Directions. International Journal of Circumpolar Health, 67(2-3):179-189. 